\title{
Novas Propostas Pedagógicas para o Desenvolvimento de Disciplinas Ministradas em Línguas Estrangeiras nas Salas de Aula Multiculturais
}

\author{
New Proposals for Educational Development of Disciplines \\ Taught in Foreign Languages in Multicultural Classrooms
}

Luciane Stallivieri

Doutora em Línguas Modernas. Universidade Federal de Santa Catarina. Florianópolis, SC. Brasil. E-mail: luciane.stallivieri@ufsc.br

Roberto Birch Gonçalves

Doutor em Administração. Universidade de Caxias do Sul. Caxias do Sul, RS. Brasil.E-mail: rbgoncal@ucs.br

\section{Resumo}

Este estudo discorre sobre a atual tendência da oferta de disciplinas de graduação, ministradas em línguas estrangeiras, fundamentais para a formação dos profissionais globais, que necessitam de competências diferenciadas para atuação em mercados multiculturais. Fez-se uma reflexão sobre os conceitos de internacionalização, mobilidade acadêmica $e$ internacionalização curricular e realizou-se um estudo de caso longitudinal, num período de três anos (20102013), descrevendo a trajetória da disciplina Intercultural Communication, ministrada em língua inglesa numa sala de aula multicultural, em uma Instituição de Ensino Superior. Para análise dos resultados, foram utilizados os dados fornecidos pelo sistema de avaliação online. Os resultados mostram o grau de satisfação dos estudantes que cursaram a disciplina e colocam em relevo as competências dos profissionais que ministram aulas em línguas estrangeiras em que a habilidade com a língua é fundamental, no entanto, o domínio do conteúdo e a aplicação de metodologias adequadas não são menos importantes.

Palavras-chave: Internacionalização. Mobilidade Acadêmica. Internacionalização Curricular. Disciplinas em Línguas Estrangeiras.

\section{Abstract}

This study discusses the current trend of offering courses in the undergraduate programs, taught in foreign languages, as a fundamental aspect for the formation of new global professionals who require different skills to work in multicultural markets. To do so, the research highlights some concepts of internationalization, academic mobility and curricula internationalization. A longitudinal case study was conducted over a period of three years (2010-2013), describing the trajectory of the Intercultural Communication discipline, taught in English in a multicultural classroom, in a Higher Education Institution. For the analysis, it was used the data provided by online assessment system. The results show the degree of satisfaction by students who attended this course and emphasizes the strong responsibility of professionals who teach courses in foreign languages where language proficiency is essential, however the content domain and the use of proper methodologies are no less important.

Keywords: Internationalization. Academic Mobility. Internationalization of Curriculum. Disciplines in Foreign Languages. 


\section{INTRODUÇÃo}

As instituições de Ensino Superior estão passando por um acelerado processo de mudanças em decorrência dos movimentos resultantes do processo de internacionalização da educação. Não existe uma única definição para a internacionalização. No entanto, é consenso que o processo requer mudanças estruturais, com a inclusão da dimensão internacional na estrutura organizacional da instituição, investimento no desenvolvimento das equipes e o envolvimento de todos os membros da academia, sejam eles professores, pesquisadores, estudantes ou gestores. A internacionalização deixou de ser uma proposta externa das decisões institucionais, passando a estar no centro dos planejamentos estratégicos e de desenvolvimento institucional. (DE WITT, 1997; RUDZKI, 1998; KNIGHT, 2004; SEBASTIAN, 2004)

Um dos motores mais fortes da internacionalização é a mobilidade acadêmica que oportuniza a realização de estudos em diferentes instituições, não somente com o objetivo da aquisição de novos conhecimentos, mas acima de tudo pela oportunidade de ampliar as experiências internacionais, através da aproximação e da convivência com cidadãos de outras culturas. Desenvolvem-se, além das competências cognitivas de áreas específicas, as competências interculturais, fundamentais para o cidadão global que busca sua inserção nos mercados cada vez mais multiculturais e focados para a resolução de problemas de ordem mundial. De fato, os inúmeros conflitos nacionais, regionais, internacionais e culturais estão impondo que os professores auxiliem seus alunos na compreensão e reflexão dos relacionamentos multiculturais e seus impactos no cotidiano. (KNIGHT, 2004)

Indiscutivelmente a globalização promovida pela disseminação da informação, facilidades logísticas e uma nova ordem geopolítica implicam em novas dinâmicas organizacionais, dentre estas a intensificação da mobilidade de mão de obra. Segundo Knight (2004), a mobilidade do mercado de trabalho e o aumento na diversidade cultural das comunidades requerem que ambos, estudantes e professores tenham uma melhor compreensão e que demonstrem habilidades para trabalhar e para viver em ambientes culturalmente diferentes.

Diante disso, encontram-se diferentes perfis no corpo docente e discente e surgem novos ambientes educacionais que passam a ser frequentados por cidadãos de línguas e culturas oriundos de diversos países, decorrentes de tal mobilidade. Requerem-se, então, novos modelos pedagógicos, demandam-se revisões curriculares frequentes e que atendam às necessidades de um mercado que exige outras habilidades dos profissionais formados nos ambientes acadêmicos.

Para atender a essa demanda, é necessário formar profissionais com habilidades inovadoras de ensino-aprendizagem, com práticas pedagógicas diferenciadas para atuação nos novos cenários propostos pelos ambientes educacionais multiculturais.

$\mathrm{O}$ incremento da mobilidade acadêmica e a expansão dos ambientes profissionais e educacionais multiculturais geram a necessidade da internacionalização dos currículos, integrando uma dimensão internacional e intercultural nos conteúdos dos currículos, e se necessário, nos próprios métodos pedagógicos. (VAN DER WENDE, 1996)

A maior evidência de internacionalização curricular passa a ser a oferta de disciplinas que, não somente ofereçam conteúdos sobre as questões interculturais e de ordem mundial, mas que sejam ministradas em línguas estrangeiras, possibilitando a interação ainda maior de representantes de diferentes culturas, que podem, através de uma mesma língua, estabelecer um efetivo processo de comunicação.

Isso aponta para além das competências pedagógicas básicas necessárias ao profissional que ministrar tais disciplinas. $\mathrm{O}$ amplo domínio de línguas estrangeiras, especificamente da língua de instrução da disciplina (BANU; FIDAN, 2013; GRIGORYEVA et al., 2014), seja ela em inglês ou espanhol, estará em destaque. Mas não somente a possibilidade de expressar-se em outro idioma, o que se sobressai são as habilidades de se relacionar com pessoas de outras culturas, com base no respeito e no entendimento das diferenças, criando espaços de verdadeira integração intercultural. A prática pedagógica precisa converter-se em um instrumento que conduza o estudante a um diálogo criativo com as dúvidas e interrogações do nosso tempo, condição necessária para uma formação cidadã. (MORIN, 2005)

Sob a luz dessas reflexões, o objetivo deste trabalho é verificar quais são os fatores determinantes para que aconteça o aprendizado numa sala de aula multicultural, com ênfase na língua de instrução, nas 
habilidades do professor e na metodologia utilizada para tal fim. (GRIGORYEVA et al., 2014)

Para tanto, realizou-se um estudo de caso acompanhando o desenvolvimento $e$ as avaliações da disciplina chamada "Intercultural Communication" lecionada no curso de comércio internacional, durante cinco semestres letivos, no período de 2011-2013, analisando, especialmente, as respostas dadas pelos alunos que cursaram a disciplina.

\section{Internacionalização da EducaÇão SUPERIOR}

As instituições de Ensino Superior, que estão desenvolvendo seu processo de internacionalização, investem fortemente na qualificação de seus professores e na formação de seus estudantes, pela oferta de programas de capacitação realizados em instituições parceiras no Exterior, ao mesmo tempo em que abrem suas portas para receberem cidadãos de outras nacionalidades para participarem de seus próprios programas.

Os conceitos que sustentam essas atividades, suas derivações, as razões e a motivações que estão levando as instituições de Ensino Superior a aderirem a esse processo e, principalmente, seus benefícios, suas tendências, seus riscos e seus desafios são fundamentais para o entendimento da internacionalização. Da mesma forma, a compreensão da evolução, o acompanhamento de momentos importantíssimos da história da humanidade e também da história das instituições de Ensino Superior, desde a sua criação é indiscutivelmente necessária.

A internacionalização adquire grande destaque, no final do século XX, impulsionado fortemente pelo fenômeno da globalização. Para Knight (1994), a internacionalização das universidades é o processo de introdução da dimensão internacional na cultura e na estratégia institucional, nas funções de formação, investigação, e extensão e na projeção da oferta e das capacidades da universidade.

Sebastián (2004) considera a internacionalização como um processo cultural que se manifesta no interior das universidades, afeta as mentalidades, os valores e as percepções, dando lugar a uma visão mais ampla e universal na compreensão da realidade.
As mudanças sofridas em diferentes âmbitos sejam elas no cenário econômico, político, cultural, seja no social, provocaram mudanças no comportamento do homem e geraram a necessidade de novas respostas para condições impostas por essa sociedade globalizada.

A velocidade com que circulam as informações e a facilidade no seu acesso, a evolução na produção do conhecimento científico e tecnológico, a aproximação das diferentes cadeias e diferentes redes de pensamento, as novas descobertas que melhoram a qualidade de vida, ao mesmo tempo em que trazem soluções, geram novas demandas e novas necessidades para as populações, que acabam por interferir e construir um novo perfil de homem, de cidadão, de profissional e de agente dessa nova sociedade. Não se pode mais ignorar a urgência da universalização da cidadania, que, por sua vez, requer uma nova ética e, por conseguinte, uma escola de educação e cidadania para todos. (MORIN, 2005)

A releitura do passado nos possibilita entender os movimentos da humanidade neste momento, da mesma forma que provoca novas reflexões: por que uma vivência internacional passa a ser tão valorizada? Por que os jovens estão buscando, cada vez mais, sua formação com qualificação em outros países? Por que os currículos com experiências internacionais estão tão concorridos? Por que oferecer disciplinas em línguas estrangeiras?

Se for retomado o conceito de universidade e de universalidade do conhecimento, e se for resgatada à origem da criação das primeiras universidades, entende-se que era muito comum à realização de intercâmbios entre os estudantes e professores (CHARLE; VERGER, 1996), com a finalidade de buscar conhecimentos novos. As universidades formavam-se com características cosmopolitas e os estudantes eram peregrinos que colavam grau em diferentes instituições.

Se o passado auxilia a entender os fenômenos contemporâneos e traz essa visão, interpretar o presente, sob essa ótica, significa ler o que está sendo sinalizado como demanda da sociedade global, que valoriza uma vivência internacional, reconhece o potencial intelectual dos indivíduos; aposta na produção do conhecimento científico e tecnológico, e prioriza os conceitos de solidariedade e tolerância para a solução dos problemas vividos, $e$, principalmente, criados por essa sociedade. 
Assim, um dos grandes desafios para a educação, para os educadores e para os que conduzem a administração das instituições de Ensino Superior consiste em definir como a comunidade acadêmica, seus estudantes, seus professores, seus pesquisadores, seus gestores podem aprender a dinâmica da comunicação intercultural, desenvolver uma consciência global, aprender a cultura de outros países, atuar em ambientes multiculturais e transformarem-se em pessoas internacionais, preparadas para os desafios do futuro.

A comunidade acadêmica passa a reagir aos efeitos da globalização, por sua própria inserção nos cenários internacionais, seja devido à mobilidade, com a participação em congressos, seminários e eventos, programas de intercâmbio, seja devido à apresentação de trabalhos de cunho científico, ou, ainda, pela publicação de artigos em revistas científicas e periódicos internacionais.

A maior evidência percebida está nos resultados e no novo comportamento da academia e da sociedade científica, que reconhece, privilegia e valoriza ainda mais toda a manifestação intelectual, especialmente a que contém algum componente internacional.

A manifestação da internacionalização passa a ser percebida em todos os ambientes das instituições de Ensino Superior, ou seja, ela é necessariamente uma manifestação transversal que contempla além do conhecido tripé da educação superior, ensino, pesquisa e extensão, também as atividades de gestão.

A internacionalização deixa de ser externa à vida acadêmica e passa a estar no escopo das decisões políticas e estratégicas dos conselhos superiores institucionais. Deixa de ser uma opção e passa a ser um objetivo a ser atingido, com evidentes razões para isso, oportunizar experiências internacionais para toda a comunidade em busca da excelência e da qualidade acadêmica. (STALLIVIERI, 2009)

\section{Mobilidade Acadêmica Internacional}

A mobilidade acadêmica passa a ser um diferencial competitivo aos estudantes que buscam seu ingresso no mercado de trabalho. Está evidente que além dos ganhos já reconhecidos como a habilidade de comunicação em línguas estrangeiras, o estudante que vivencia uma experiência internacional desenvol- ve a sua sensibilidade intercultural, tornando-se mais tolerante, mais flexível, mais solidário e demonstrando ser possuidor de elevado grau de empatia com relação às dificuldades do outro.

As instituições, por sua vez, passam a repensar o seu papel na formação de cidadãos que precisam atender às novas demandas do mercado profissional, ou seja, a busca por cidadãos globais, com competências específicas, entre elas a forte sensibilidade cultural. Bennett introduz a expressão sensibilidade cultural e a define como:

[...] um processo de crescimento pessoal do indivíduo, no seu modo de perceber e de avaliar as diferenças culturais. O indivíduo alcança níveis superiores em sua capacidade de reconhecer, de se adaptar e de aceitar as diferenças culturais. (BENNETT, 1998, p. 22)

Uma das maiores fortalezas do investimento na mobilidade acadêmica internacional está na formação de cidadãos globalmente competentes e que sejam capazes de interagir em ambientes multiculturais $e$ participar de diferentes momentos e processos de comunicação, de forma interculturalmente eficiente. A interculturalidade é um movimento social crítico frente à desigualdade; em educação, é uma das formas de atenção à diversidade, um dos elementos chaves da legislação educativa. (SÁEZ, 2006)

Para assegurar os resultados esperados, os estudantes precisam ter clareza das habilidades que estarão sendo utilizadas ou desenvolvidas a começar com o entendimento do que é o processo de comunicação intercultural até identificar o que é ser globalmente competente.

O termo intercultural communication ou comunicação intercultural foi inicialmente estudado por Hall, em sua obra The silent language, em 1959, quando delineou o esquema lógico necessário não somente para entender outra cultura, mas também compreender o funcionamento da comunicação entre pessoas de diferentes culturas.

Hall (1959) examinou especialmente os conceitos de espaço e de tempo, o conceito de comunicação não verbal e como eles determinavam a forma de relacionamento entre os indivíduos. Os estudos de Hall definiram que "[...] culture is communication and communication is culture". (HALL, 1959, p. 186), isto 
é, cultura é comunicação, comunicação é cultura. Ele realizou suas atividades profissionais em Washington DC para o Foreign Service Institute, onde teve a oportunidade de desenvolver programas voltados para capacitar os funcionários e os diplomatas norte-americanos, que precisavam deslocar-se ao Exterior para atividades profissionais. Hall identificou que esses profissionais necessitavam formas eficazes de comunicação e de interação com as diferentes culturas das comunidades locais, o que gerou a necessidade de um estudo sistemático, que retomasse os estudos feitos por Boas (1911) e por Sapir (1949) sobre o relativismo cultural, porém colocando luz a uma nova reflexão.

A urgência de entender a forma como a comunicação ocorre entre os falantes de línguas diferentes, mas que também utilizam manifestações culturais extremamente diferentes fomentou a necessidade de elaboração de estudos sistemáticos sobre esse tema.

A comunicação intercultural é, pois, considerada a troca de informações entre indivíduos que são diferentes culturalmente (ROGERS; STEINFATT, 1999). Essa ampla definição pressupõe que dois ou mais indivíduos podem ser considerados diferentes na mesma cultura nacional, etnicidade, idade, gênero, ou em outras formas que podem afetar sua interação.

O conhecimento aprofundado de uma língua estrangeira não é suficiente para garantir a comunicação eficaz entre dois falantes se o usuário não souber utilizá-la em situações reais de comunicação, pois a "[...] comunicação não garante a compreensão". (MORIN, 2005, p. 94)

Deve-se conhecer a indissociabilidade dos conceitos de língua e cultura e saber que é fundamental conhecer sua própria cultura para depois entender a cultura do outro, procurando, acima de tudo, compreendê-la e respeitá-la como ela é, porém sem valer-se do etnocentrismo, que é o grau com o qual os indivíduos julgam outras culturas como sendo inferiores a sua própria.

O Conselho da Europa publicou, no ano de 2001, um documento que objetiva servir de ponto de conexão para a prática e a didática da língua em toda a Europa, nominado Quadro Europeu Comum de Referência das Línguas (QECR). O QECR (2001) descreve de forma integradora o que devem aprender os estudantes de línguas com a finalidade de utilizar uma língua para fins de comunicação, assim como os conhecimentos e destrezas que tem que desenvolver para poder atuar de maneira eficaz.

Os autores colocam os conceitos de comunicação intercultural e de relativismo cultural com clareza; porém as instituições de Ensino Superior, salvo algumas exceções, ainda não despertaram para a necessidade de preparar os estudantes para as vivências internacionais, sejam elas no Exterior ou no próprio país. Eles entendem que é um dos maiores desafios para a educação do futuro, porém as estruturas permanecem inalteradas, contando apenas com alguns ajustes administrativos para a saída dos estudantes ao Exterior, quando deveriam debruçar-se fortemente nos estudos e discussões sobre a internacionalização curricular.

\section{Internacionalização Curricular}

Ambientes multiculturais ou pluriculturais, formados por pessoas de diferentes raças, nacionalidades, religiões e, obviamente, multilíngues ou plurilíngües. Essa é uma realidade cada vez mais próxima e passa a fazer parte de um novo universo, seja ele no âmbito profissional, seja no acadêmico ou social.

Transitar e conviver confortavelmente com cidadãos que falam outras línguas e que originam de diferentes culturas é uma característica cada vez mais valorizada e deve ser pensada como parte integrante dos diferentes ambientes de ensino e das diferentes formas de ensinar. Se os conceitos de língua e cultura estão totalmente interligados, é impossível trabalhar com uma delas sem que a outra esteja presente.

Desde as colocações de Sapir, em 1921, "language does not exist appart from culture", ou seja, a língua não existe separada da cultura, a reflexão volta-se para o tipo e forma de cultura que deve ser desenvolvida, principalmente em ambientes formais de ensino geral ou de ensino de línguas estrangeiras, bem como nos ambientes educacionais que objetivam a formação de cidadãos globalmente competentes.

Para o QECR (2001), as competências plurilíngues e pluriculturais fazem referência à capacidade de utilizar as línguas para fins comunicativos e de participar em uma relação intercultural em que uma pessoa, enquanto agente social domina - com determinado grau - várias línguas e possui experiência de várias culturas. 
Nesse sentido, Gacel-Avila (2003) aponta que existem limitações nos atuais sistemas de ensino de idiomas, e que por essa razão, o ensino deve ser acompanhado do conhecimento do contexto cultural e social no qual está imerso.

O ambiente de aprendizagem da segunda língua é altamente motivador para a aquisição de aspectos culturais fundamentais para a formação do indivíduo e para o seu entendimento sobre o comportamento dos outros povos (TAHA, 2014), especialmente para a formação de profissionais que atuarão em mercados globais, em que estarão convivendo com novas manifestações linguísticas e comportamentais.

Não basta que o profissional se torne bilíngue, ele deve se tornar, também, plurilíngue e pluricultural. Com esse novo quadro de referência, o usuário da língua utiliza dois tipos de competências: competências gerais de um indivíduo e competências comunicativas da língua. As competências gerais são aquelas em que o usuário pode recorrer a ações de todo o tipo, incluindo atividades comunicativas, sem ser necessariamente linguísticas. As competências comunicativas são as que capacitam uma pessoa para atuar por meios comunicativo-linguísticos.

Dentre as competências gerais do usuário, o quadro de referência dedica um expressivo espaço para as destrezas e habilidades (do saber ser), dividindo-as entre destrezas e habilidades práticas (sociais, da vida, profissionais e de ócio) e destrezas e habilidades interculturais.

A capacidade de relacionar entre si, a cultura de origem e a cultura estrangeira, a sensibilidade cultural e a capacidade de identificar e utilizar uma variedade de estratégias, para estabelecer contatos com pessoas de outras culturas; a capacidade de atuar como intermediário cultural entre a cultura própria e a cultura estrangeira e de abordar com eficácia os mal-entendidos interculturais e as situações conflitivas e a capacidade de superar relações estereotipadas são as destrezas identificadas pelo QECR (2001), no momento em que os estudos de interculturalidade são mais necessários e estão mais evidentes do que nunca.

Os programas de ensino de disciplinas específicas e os programas de línguas estrangeiras devem permitir que os estudantes experienciem também situações de imersão na nova cultura com a qual estão tendo contato.
A internacionalização curricular, por meio de uma abordagem intercultural para os programas de ensino comum e para o ensino de línguas estrangeiras requer a aceitação de novos conceitos e valores trazidos pelas outras culturas. A importância da definição das condições e dos ambientes em que a cultura será trabalhada é fundamental, ou seja, promover seu entendimento e não confronto a elas.

O desenvolvimento de atividades que levam o aprendiz a "praticar a linguagem gramaticalmente correta e a compreensão da cultura politicamente aceita" são conceitos que devem ser revistos, pois se língua e cultura são indissociáveis, a ênfase deve ser dada ao ensino das diferentes formas culturais em determinadas situações, observando principalmente os aspectos e os contextos envolvidos no momento da comunicação.

Um enfoque crítico da cultura é necessário, no qual os conceitos de multiculturalidade e de interculturalidade representam eixos de pensamento, ou seja, é a cultura pensada com seus valores, mediante a comparação de estudos etnográficos, a fim de compreender tanto a língua materna quanto a cultura materna, proporcionando, dessa forma, a possibilidade de gerar reflexões acerca das relações dos indivíduos e da sociedade num mundo marcado pela diversidade.

Desponta, então, como forte tendência na educação a oferta de disciplinas ministradas em línguas estrangeiras, prioritariamente em língua inglesa, cujas políticas linguísticas favorecem cada vez mais a sua proliferação como a língua da comunicação global ou a língua dos mercados econômicos e dos negócios.

Não se apresentam apenas as dificuldades inerentes à disciplina, relacionadas somente com o seu conteúdo, mas também as dificuldades linguísticas (BANU; FIDAN, 2013), tais como: forma de expressão, entonação, velocidade da fala, sotaque, intensidade do vocabulário, comunicação verbal e não-verbal, entre outras.

Por outro lado, a forte competitividade no setor educacional faz com que as instituições de ensino superior também depositem nos novos ambientes acadêmicos a possibilidade de assegurar seu espaço no cenário da educação global, tornando-se mais atrativas para a captação de professores e de pesquisadores, mas, sobretudo, de estudantes estrangeiros que viajam em busca de vivências internacionais. 
Isso, de certa forma, faz com que o ambiente mundial da educação superior esteja se aproximando do ambiente empresarial, sofrendo uma intensificação concorrencial fruto, principalmente, das possibilidades tecnológicas e logísticas que promovem ensino a distância, intercambio de professores e alunos, integração entre as instituições como forma de ampliar a pesquisa e os relacionamentos.

No cerne dessa questão é possível observar a comercialização do ensino $e$ as possibilidades de capitalização das IES. É comum que os países mais desenvolvidos em alguma área da educação superior tenham na exportação de suas metodologias uma fonte de renda com mercado em diversos países, em especial, os países em desenvolvimento.

No entanto, os países emergentes como o Brasil também podem fazer uso da sala de aula em outra língua, buscando captar estudantes de outros países que objetivam trabalhar, negociando com o Brasil. Assim, além de ampliarem seu conhecimento compreendem os aspectos culturais que melhoram suas habilidades em negociar futuramente. Esse fato pode tornar-se uma fonte de recursos para as IES brasileiras e uma forte possibilidade de projeção com melhores instituições do mundo.

Observa-se que os benefícios com as salas de aulas multiculturais e com a oferta de disciplinas em línguas estrangeiras podem ser inúmeros, mas que também várias podem ser as dificuldades, pois a forma e a preparação do professor para conduzir uma sala de aula com aspectos multiculturais podem ser decisivas, além de ser o fator determinante de êxito.

\section{Disciplinas Ministradas em Línguas ESTRANGEIRAS}

A comunicação pode ser fator impeditivo no momento de levar adiante as propostas de internacionalização curricular. A comunicação pode ser fator impeditivo no momento de levar adiante as propostas de internacionalização curricular, pois, a escolha da língua impactará o processo de capacitação dos professores e as demais condições de gerenciamento desta internacionalização.

Para Graddol (2006, p. 62), "English is by no means the only language in global business". Ou seja, há unanimidade de que a língua inglesa é a língua de comunicação no mundo dos negócios.

De Witt reforça o posicionamento afirmando que a língua inglesa está se tornando a língua de comunicação global nas tecnologias, negócios, cultura, sociedade, ciência e educação. Existem dezenas de línguas no mundo que servem como línguas centrais subcontinentais, línguas que operam como línguas terceiras de comunicação nas suas regiões. "[...] A exportação da língua inglesa está relacionada com a posição que ela ocupa, juntamente com a cultura, na rede global de intercâmbios [...]". (DE WITT, 1997, p. 167)

Atentos a esses movimentos, o British Council e o Centro de Pesquisas em Educação da Oxford University, em 2014, estão realizando um estudo com o objetivo de compreender o fenômeno que está ocorrendo com relação à mudança do ensino do inglês como língua estrangeira (English as a Foreign Language - EFL) para o uso do inglês como meio de instrução (English as a Medium of Instruction - EMI).

O documento intitulado English as a Medium of Instruction (EMI): a growing global phenomenom prevê, em sua introdução, que existe um crescente movimento, em nível mundial, da introdução da língua inglesa como língua de instrução de conteúdos acadêmicos, como matemática, ciências, geografia, realizado pelos professores em universidades, escolas primárias e secundárias. As implicações desse movimento são muito importantes para a educação e especialmente para o posicionamento dos países não anglófonos. Questões relevantes devem pautar as observações desse fenômeno, analisando, especialmente quais serão as consequências da entrega de conteúdos em línguas estrangeiras para o ensino, para o aprendizado e para o desenvolvimento profissional dos professores. (DEARDEN, 2014)

Por se tratar de um fenômeno recente, ainda pouco se estudou sobre o ensino de disciplinas regulares ministradas em outras línguas oferecidas em cursos de graduação. O estudo do British Council já aponta para algumas conclusões e sinaliza para algumas questões fundamentais para posteriores discussões. Quanto às conclusões, após investigação realizada com representantes de 55 países, o estudo afirma que o EMI é um fenômeno crescente, visto como um passaporte para o mundo globalizado. As razões para o ensino de conteúdo acadêmico através da língua inglesa são as mais 
diversas, sendo que para os professores que ministram as disciplinas, a proposta ainda passa por idealismos, ou seja, uma forma de melhorar a sua comunicação, estabelecer relações com outros países e promover uma cultura de paz. Já para os estudantes, aprender os conteúdos em língua inglesa, significa uma forma de abrir portas para o mundo de negócios, para o desenvolvimento de carreiras profissionais bem-sucedidas.

Apesar de haver controvérsias sobre a opinião pública, que ainda defendem o ensino com a língua local por questões de preservação da cultural local; para os dirigentes das instituições de ensino superior, a questão passa a ser considerada uma forma de globalização e de garantir a internacionalização, necessária para a sobrevivência de muitas instituições.

Uma das mais importantes dificuldades para o uso do EMI está na identificação de profissionais com a formação adequada para a realização de tal atividade. É ainda um grande desafio para as IES localizarem nos seus quadros profissionais que reúnam as competências necessárias para o ensino de disciplinas em línguas estrangeiras, ou seja, alto grau de comprometimento com a nova tarefa, proficiência no idioma em questão, domínio dos conteúdos, conhecimento de metodologia desenvolvida para tal fim, identificação de materiais educacionais que sirvam para o conteúdo a ser trabalhado em sala de aula com os alunos proficientes, além da capacidade de estabelecer bom relacionamento com representantes de outras culturas.

Isso é corroborado pelo estudo do British Council que reforça, em suas conclusões, ainda a ausência na maioria das instituições de políticas claras para a oferta e para a entrega dos conteúdos de disciplinas em língua inglesa (lack of clear guidelines on how to deliever education through EMI), bem como a ausência de materiais instrucionais (lack of teaching resources).

Entre todos os achados do estudo, forte atenção é dada ao perfil do professor e de suas competências, uma vez que, ao serem entrevistados para a pesquisa, ficou claro que eles não são falantes nativos e desconhecem as exigências mínimas para ministrar disciplinas em línguas estrangeiras, como nível de proficiência mínimo necessário ou testes e qualificações para o desempenho da função. Os professores também não tem clareza com relação aos critérios para a atividade, uma vez que foram selecionados para o ensino de disciplinas em línguas estrangeiras pelo fato de terem tido uma experiência internacional anterior, ou seja, moraram fora do seu país de origem, falam bem a língua ou simplesmente se voluntariou para o trabalho, o que não garante as competências metodológicas necessárias a esse tipo de atividade. (DEARDEN, 2014)

Como todo novo fenômeno, a oferta de disciplinas em línguas estrangeiras ainda não possui um contorno definido, apesar de grandes movimentos sendo feitos nessa direção por várias universidades. É importante estudar e acompanhar casos bem-sucedidos e monitorar os resultados decorrentes dele, para poder ampliar a oferta dessas disciplinas de forma responsável e coerente. Não basta transpor os conteúdos de uma disciplina para a língua estrangeira em questão. A instituição, os professores e os alunos tem que ter clareza de todas as implicações que movimentos dessa magnitude podem gerar no processo econômico, político, social e educacional.

\section{Procedimentos Metodológicos}

Considerando o objetivo do presente estudo, realizou-se uma pesquisa qualitativa para avaliar a percepção dos estudantes de graduação com relação à disciplina Intercultural Communication, ministrada em Língua Inglesa, para acadêmicos do curso de Comércio Internacional. Procedeu-se um estudo de caso (YIN, 2005), descrevendo a trajetória dessa disciplina numa sala de aula multicultural num período de três anos (2010-2013), em uma Instituição de Ensino Superior. Optou-se pelo estudo de caso, pois é uma investigação empírica que investiga um fenômeno contemporâneo dentro de seu contexto da vida real, especialmente quando os limites entre o fenômeno e o contexto não estão claramente definidos (YIN, 2005) que foi o ambiente envolvido neste estudo.

\subsection{Coleta de Dados}

Para coleta de dados, utilizaram-se os dados fornecidos pelo sistema de avaliação on-line validado pela Instituição desde 2002. A avaliação on-line dos cursos de graduação da universidade é realizada semestralmente, desde 2002. Como parte da rotina acadêmica, esse processo avaliativo se consolida como um procedimento importante e necessário para a 
qualificação dos cursos de Graduação. Também é um processo decisivo para subsidiar a tomada de decisões nos diversos âmbitos de gestão.

A avaliação on-line envolve alunos, professores, gestores acadêmicos e funcionários. Os questionários aplicados aos alunos contemplam as seguintes questões: O professor estabelece um relacionamento de respeito e valorização do aluno? O professor conhece sua área de atuação e estabelece relações com áreas afins? O professor desenvolve as aulas de forma planejada? O professor utiliza diferentes estratégias para promover aprendizagem? (tarefas, atividades, exercícios, cases, problemas, simulações, pesquisas, etc.). O professor articula situações de ensino com aspectos do cotidiano e da futura atuação profissional? $\mathrm{O}$ professor utiliza os resultados das avaliações (provas, trabalhos, tarefas, exercícios) como recurso para melhorar a aprendizagem? O professor utiliza o tempo de aula de forma proveitosa para as atividades de ensino e de aprendizagem na disciplina?

Os questionários possibilitam que os alunos escolham a pontuação de 1 a 5 , sendo 5 a resposta de maior valor, correspondendo ao conceito máximo - ótimo. O questionário possibilita, também, que os alunos possam manifestar a sua opinião para cada item avaliado, sendo que não é necessária a identificação do respondente no momento do preenchimento das avaliações, dando maior liberdade nas manifestações das respostas.

O monitoramento dos resultados foi realizado entre os anos 2011 e 2013, perfazendo um total de 10 turmas avaliadas em cinco semestres, uma vez que a disciplina é oferecida para dois grupos distintos a cada semestre.

\subsection{Procedimentos de Análise}

Para análise dos dados foram utilizados os relatórios fornecidos pela comissão de avaliação no período de 2011 a 2013. Além disso, realizou-se uma categorização das respostas descritivas para que fosse possível realizar uma análise de conteúdo. (BARDIN, 2005)

As categorias analisadas são: autoavaliação do aluno e avaliação do professor pelos alunos.

As questões analisadas foram respondidas pelos alunos, que serão chamados de Respondentes, identificados por $\mathrm{N}$, seguidos da informação do ano e do semestre em que participaram da pesquisa, ou seja: N1 12-1 significa que foi o aluno N1 que respondeu o questionário no primeiro semestre no ano de 2012.

\section{Análise dos Dados}

A IES utiliza a avaliação on-line para obter um diagnóstico mais preciso sobre a realidade de cada curso e, consequentemente, viabilizam a tomada de decisões voltadas para o aprimoramento das ações da Universidade no âmbito do ensino de graduação. É um instrumento que faz da agilidade na aplicação, análise e devolução de resultados, um aspecto imprescindível, tornando-se um instrumento efetivo na cultura acadêmica.

O curso avaliado foi o de Comércio Internacional que, de acordo com o Projeto Pedagógico, foi criado para alunos que buscam uma formação interdisciplinar, que tenham interesse por história, geografia, cultura, línguas, economia, administração, direito, logística e finanças, estudantes proativos, curiosos, interessados em conhecer o que há além das fronteiras de sua cidade e seu país, dispostos a assumir riscos e abertos a diferentes culturas e diferentes formas de ver o mundo. Estudantes capazes de aprender e empreender.

Buscando a formação de profissionais globais, capacitados para atuação em mercados multiculturais, foi criada a disciplina nomeada de Intercultural Communication, ministrada em língua inglesa. A disciplina objetiva desenvolver as habilidades e competências globais para a efetiva comunicação intercultural no ambiente empresarial, identificando as diferentes formas de comunicação e de linguagem utilizadas pelas diferentes culturas, especialmente em ambientes formais de negociações internacionais. Possibilita ao aluno entender as diferentes formas de manifestação cultural, analisando criticamente as manifestações de preconceitos raciais, religiosos, entre outros (TAHA, 2014). Busca, também, desenvolver habilidades para resolução de conflitos internacionais e busca para solução de problemas ou de obstáculos em ambientes de negociações multiculturais através da inteligência. O estudante passa a compreender os conceitos de cultural shock, cultural shock reverse, cultural iceberg e as diferentes formas de adaptação no Exterior, a fim de se preparar para se tornar um global managers em am- 
bientes multiculturais nas empresas internacionalizadas e em situações de vivências diárias nos diferentes países (GACEL-AVILA, 2003; KNIGHT, 2004; SEBASTIÁN, 2004). Através da presença de convidados estrangeiros, situações reais de trocas interculturais são experienciadas, preparando para atuação profissional nos ambientes internacionais. Capacitar os profissionais para atuação em diferentes situações com representantes de outras nacionalidades de forma positiva e bem-sucedida, evitando os conflitos e desentendimentos por questões raciais ou preconceituosas estão no cerne das discussões da sala de aula multicultural.

Para a realização da disciplina, o grupo é formado prioritariamente por estudantes do curso de graduação em comércio internacional, comprovadamente proficientes em língua inglesa. No entanto, estudantes de outras áreas do conhecimento também se matriculam na disciplina, tendo em vista o caráter interdisciplinar que ela apresenta. Sendo assim, estudantes dos cursos de relações internacionais, relações públicas, administração, letras, enfim, todas as áreas que visam à formação de profissionais que buscam a atuação em cenários multiculturais. Essa diversidade de áreas de conhecimento enriquece sobremaneira o desenvolvimento da disciplina, uma vez que coloca profissionais com diferentes olhares sobre as questões interculturais.

Ressalta-se a fundamental importância da participação dos estudantes estrangeiros, uma vez que a sua presença corrobora as diferenças culturais estudadas, aprofunda discussões sobre temas específicos, tais como estereótipos, diferenças religiosas, etnicidade, multiculturalismo e demais tópicos vinculados os diferentes hábitos, crenças e valores das diferentes culturas.

Conceitos relacionados com a comunicação como força propulsora dos negócios, conceitos, tipos e formas de comunicação, comunicação e cultura, comunicação intercultural, comunicação verbal $e$ comunicação não verbal, a influência da forma de comunicação nas diferentes culturas, conceito de choque cultural e choque cultural reverso ou stress aculturativo, relativismo cultural, identidades culturais, ambientes multiculturais de comunicação e de negócios, desenvolvimento da inteligência cultural e da sensibilidade intercultural são alguns dos temas referenciais da disciplina. Análise dos perfis de um global manager, os fracassos e insucessos nas relações interculturais norteiam as discussões, que são apresentadas de forma interativa, através das quais os estudantes colaboram intensamente. Para tanto, são analisados o papel do negociador e suas implicações na diferentes culturas, as formas, os estágios de negociação internacional, mas acima de tudo as trocas culturais que ocorrem durante a negociação e os elementos que fazem uma negociação e um negociador de sucesso, provido da consciência intercultural e da necessidade de compreender e aceitar as diferenças do outro.

Em todas as avaliações on-line realizadas no período de 2011 a 2013, a disciplina Intercultural Communication recebeu o conceito ótimo, indicando um alto grau de satisfação dos alunos com relação ao trabalho desenvolvido.

Buscou-se compreender os fatores que receberam maior relevância na manifestação da opinião dos alunos com relação à disciplina e alguns elementos foram evidenciados. Foram classificados em seis categorias, dada à repetição das opiniões e dos termos empregados pelos alunos. As categorias relatadas são: língua de instrução, metodologia, materiais instrucionais, recursos utilizados, perfil do grupo e perfil do professor.

De acordo com os respondentes, existe alta valorização pelo fato da disciplina ser ministrada em língua inglesa, fundamental para o profissional do comércio internacional, conforme pode ser comprovado pelas respostas fornecidas pelos entrevistados apresentadas a seguir: N1 11-1 "[...] fez com que eu realmente me sentisse no curso de Comércio Internacional, pelo fato de falarmos inglês, e também pela vivência com pessoas de outros países [...]"; N1 12-2 "[...] aula altamente produtiva, e o melhor de tudo, em inglês!!!". N1 12-1 "[...] achei ótimo o fato da disciplina ser toda em inglês"; N2 12-1 "[...] grande parte do curso deveria ser no estilo dessa disciplina, utilizando diferentes idiomas durante as aulas".

Destaque foi dado para a metodologia utilizada para a apresentação dos conteúdos, de forma interativa, com multiplicidade de atividades, como dinâmicas de grupo, estudos de caso, apresentação e discussão de filmes com cenas que abordam diferenças culturais, atividades em pares, pequenos grupos, utilização da metodologia de story telling, relatando as vivências internacionais, tornando os encontros interessantes e agradáveis. De acordo com os respondentes: N1 13-1 "[...] aula interessante e participativa, nunca fico entediado"; N2 12-2 "[...] Aulas super bem planejadas, 
dinâmicas, diversificadas, repletas de exemplos tanto verbais quanto físicos". N3 12-1 "[...] sempre tem algo novo na aula o que a torna muito dinâmica". N2 11-1 "[...] tem sempre alguma história, algum fato, alguma prática para fazer com que a turma entenda o conceito da matéria". N2 13-1 "[...] apresenta o conteúdo de forma dinâmica e promove a interação entre os alunos brasileiros e estrangeiros".

A utilização de materiais autênticos, extremamente atuais e de circulação internacional desperta ainda mais o interesse dos estudantes e os coloca em contato direto com a realidade dos cenários globais. A manifestação dos estudantes reforça este aspecto: N4 12-1 "[...] além de muito criativa, sempre busca coisas novas como vídeos, charges, materiais [...]". N5 12-1 "[...] as aulas são dinâmicas, com estudos de caso, vídeos, e temos contato com estrangeiros, essencial para ampliar nosso conhecimento sobre as culturas do exterior".

A presença de estudantes de diferentes nacionalidades, culturas e línguas oferece uma nova realidade educacional (VAN DER WENDE, 1996), possibilitando diferentes olhares sobre um mesmo tema. Estudantes que participam de programas de mobilidade acadêmica internacional, regularmente matriculados na disciplina, colaboram efetivamente para o êxito das atividades, uma vez que manifestam suas opiniões sobre temas polêmicos e que fazem parte das discussões propostas em sala de aula, através de leituras prévias e de outros materiais disponibilizados previamente. A opinião dos respondentes atesta isso como um dos pontos altos da disciplina. N3 13-1 "[...] Dividir experiências com colegas estrangeiros torna a aula muito rica e proveitosa". N4 13-1 "[...] Disciplina muito válida e enriquecedora por promover o encontro com diversas culturas, o que representa um grande aprendizado tanto pessoal como profissional". N3 12-2 "[...] A proposta de toda semana ter um convidado estrangeiro é ótima". N4 12-2 "[...] Achei maravilhoso ter contato com convidados de outros países, colegas estrangeiros [...]". N6 12-1 “[...] toda aula temos uma experiência internacional com pessoas de outros países para que possamos aprender mais sobre a cultura dos outros países".

O amplo conhecimento do conteúdo e o proficiente domínio da língua por parte do professor é fator fundamental para o desenvolvimento da disciplina (DEARDEN, 2014), sendo que a fluência deve estar assegurada nas cinco habilidades, leitura, escrita, fala, compreensão e conhecimento intercultural. Os respondentes se manifestaram crítica e positivamente da seguinte forma: N3 13-1 "[...] tem pleno domínio da língua e conhecimentos gerais muito amplos, o que possibilita a discussão dos mais variados assuntos em sala de aula". N5 12-2 "[...] tem total domínio do conteúdo aplicado"; N7 12-1 "[...] alto nível de conhecimento em sua área de atuação e ótimo aproveitamento de ensino relacionado ao objetivo da disciplina"; N8 12-1 "[...] conhecimento altíssimo, inglês perfeito e sabe se comunicar com os alunos criando um ambiente extremamente agradável de aprendizagem"; N9 12-1 "[...] tem alto conhecimento do mercado mundial, o que tem tudo a ver com a disciplina". N3 11-1 "[...] detém muito conhecimento na área, pessoa extremamente habilitada".

Pelas respostas dos alunos, que sinalizam para os excelentes resultados da disciplina, o papel do professor fica evidenciado, apontando para o seu domínio da língua de instrução, no caso a língua inglesa, seu profundo conhecimento do conteúdo apresentado, a utilização de metodologias inovadoras e a forte interação proporcionada pela presença de estudantes estrangeiros.

O levantamento dessas características reforça a necessidade da adequada preparação dos profissionais que ministrarão disciplinas em línguas estrangeiras, uma vez que as mesmas requerem não somente a sobreposição dos conteúdos, mas uma gama de outras habilidades e competências que possam assegurar que iniciativas dessa natureza sejam coroadas de êxito $e$ mereçam destaque na grade curricular.

A disciplina cumpre o seu papel de formar cidadãos preparados para os desafios globais (KNIGHT, 2004; SEBASTIÁN, 2004), da mesma forma que reforça o compromisso da instituição de avançar no seu processo de internacionalização, respondendo às exigências da globalização, formando cidadão não somente competentes, mas acima de tudo conscientes da cidadania global.

\section{Considerações Finais}

A presente pesquisa objetivou compreender a percepção dos acadêmicos do curso de Comércio Internacional com relação à disciplina Intercultural 
Communication, ministrada em língua inglesa, com o objetivo de identificar os elementos que a colocam com elevada avaliação, buscando compreender especialmente o fundamental papel exercido pelo professor nesse processo.

Identificou-se que o conjunto de fatores como: adequação, relevância e atualização dos conteúdos; a dinâmica das atividades; o domínio dos assuntos tratados; a língua de instrução e a presença constante de alunos de outras nacionalidades são fatores fundamentais para o êxito da disciplina.

O papel do professor, como orquestrador de todos esses elementos está em destaque, uma vez que além do domínio da língua, ele necessita ter conhecimento aprofundado do conteúdo a ser ministrado (VAN DER WENDE, 1996; DEARDEN, 2014; GRIGORYEVA et al., 2014). Ele mesmo deve ter as competências necessárias para um profissional global, capaz de discutir questões internacionais, abordar questões interculturais (GACEL-AVILA, 2003; KNIGHT, 2004) com o discernimento de que não existe uma cultura melhor do que a outra, respeitando as suas diferenças, sabendo que, não é somente possível, mas fundamental, nos novos cenários profissionais e educacionais, compreender a forma de agir, de sentir e de pensar dos outros povos, com o objetivo de buscar a solução para problemas comuns, independente da língua, raça ou do credo dos demais seres humanos que habitam o mesmo planeta.

Este estudo denota a necessidade de pesquisas aprofundadas sobre o tema com o objetivo de discutir as razões para o ensino de conteúdos em línguas estrangeiras, o perfil dos estudantes, o conteúdo e as atividades a serem desenvolvidas, a metodologia, e acima de tudo as competências e habilidades dos professores que ministrarão as aulas (DEARDEN, 2014), sendo que a dificuldade maior ainda é obter-se as duas características num mesmo profissional, ou seja a proficiência no idioma e o domínio dos conteúdos específicos. Ainda, mas não menos importante, está o entendimento de que as instituições de Ensino Superior não devem apenas responder aos modismos impostos pela internacionalização, mas sim, responder aos desafios dos cenários globalizados, coerentemente discutindo a inclusão das disciplinas em línguas estrangeiras, não somente através da substituição da língua portuguesa pela língua de comunicação global, mas adequando as estruturas, preparando seus profissionais e realmente trabalhando maduramente com vistas à internacionalização curricular.

\section{REFERÊNCIAS}

BARDIN L. Análise de conteúdo. 3. ed. Lisboa: Ed. 70; 2008.

BENNETT, Milton. Basic concepts of intercultural communication: selected readings. Yarmouth: Intercultural Press, 1998.

BANU Inan; FIDAN Dilek. Teacher Questions and their Functions in Turkish as a Foreign Language (TFL) Classes. Procedia - Social and Behavioral Sciences, Antalaya/ Turkey, v. 70, n. 25, p. 1.070-1.077, January, 2013.

\section{BOAS, Franz. Introduction: Handbook of American}

Indian languages. Washington DC: Bureau of American Ethnology, 1911. (v. 40)

BRITISH COUNCIL. [2014]. Disponível em: < http://www. britishcouncil.org >. Acesso em: 23 set. 2014.

\section{CHARLE, Christophe; VERGER, Jacques. História}

das universidades. São Paulo: Universidade Estadual Paulista, 1996.

CONFERÊNCIA Mundial sobre o Ensino Superior, Paris, 1998. Tendências de educação superior para o século XXI. Paris: UNESCO/Crub, 1998.

DEARDEN, Julie. English as a Medium of Instruction: a growing global phenomenom - phase 1. [2014]. Disponível em: <www.britishcouncil.org/education/ihe>. Acesso em: 2 out. 2014.

DE WIT, Hans. Internationalization of higher education in the United States and Europe. Westport, CT: Greenwood, 2002.

Internationalization of higher education in the United States of America and Europe: a historical, comparative, and conceptual analysis. Greenwood Studies in Higher Education, 2002.

Rationales for internationalization of higher education. [1997]. Disponível em: <http://www.ipv.pt/ millenium/wit11.htm>. Acesso em: 10 jul. 2014. 


\section{GACEL-AVILA, Jocelyne. La internacionalización de} la educación superior: paradigma para una Educación Global. México: CUSCH - Universidad de Guadalajara, 2003.

GRADDOL, David. English next. Plymouth: British Council, 2006.

GRIGORYEVA Elena Valeryevna et al. Designing technology of foreign language teaching content based on international component. Life Science Journal, Zhengzhou, v. 11, n. 9, p. 580-586, 2014. Disponível em: <http://www.lifesciencesite.com>. Acesso em: 10 jul. 2014

HALL, Edward T. Beyond culture. New York: Anchor Books, 1989.

The hidden dimension. Garden City: Anchor Books, 1969.

The silent language. Doubleday: Anchor Books, 1973.

KNIGHT, Jane. An internationalization model: responding to new realities and challenges. In: DE WIT, Hans et al. (Ed.). Higher education in Latin America: the international dimension. Washington, DC: The World Bank, 2005.

KNIGHT, Jane; DE WIT, Hans. Internationalization of higher education: a conceptual framework. In: KNIGHT, Jane; DE WIT, Hans. (Ed.). Internationalization of Higher Education in Asia Pacific Countries. Amsterdam: European Association for International Education, 1997.

Internationalization remodeled: definition, approaches, and rationales. Journal of Studies in International Education, Antalaya/ Turkey, v. 8, n. 1, 2004.

MORIN, Edgar. Os sete saberes necessários à educação do futuro. São Paulo: Cortez, Unesco, 2005.

\section{QUADRO EUROPEU COMUM DE REFERÊNCIA}

DAS LÍNGUAS. Common European Framework of Reference for Languages: learning, teaching, assessment. Conselho da Europa, 2001. Disponível em: <http://www.coe.int/T/DG4/Linguistic/Source/Framework EN.pdf $>$. Acesso em: 10 set. 2014.
ROGERS, Everett M.; STEINFATT Thomas M. Intercultural communication. Long Grove: Waveland Press, 1999.

RUDZKI, R. E. The strategic management of internationalization: towards a model of theory and practice. Thesis submited for the Degree of Doctor of Philosophy at the School of Education. University of Newcastle upon Tyne, United Kingdom, 1998.

SÁEZ, Fernando Trujillo. Cultura, comunicación y lenguaje: reflexiones para la enseñanza de la lengua en contextos multiculturales. Granada: Ediciones Magina, S.L., 2006.

\section{SEBASTIÁN, Jesús. Cooperación e} internacionalización de las universidades. Buenos Aires: Biblos, 2004.

\section{SAPIR, Edward. Selected writings of E. Sapir in} language, culture and personality. Berkeley: University of California Press, 1949.

\section{STALLIVIERI, Luciane. As Dinâmicas de uma nova} linguagem intercultural na mobilidade acadêmica internacional. Tese de Doutorado. Universidad del Salvador - USal. Buenos Aires, 2009.

TAHA, Aliaa Anis. Teaching a Foreign Language from a Cultural Perspective. Procedia - Social and Behavioral Sciences, Antalaya/ Turkey, v. 136, n. 9, p. 208-212, July, 2014.

UNESCO. Educação superior: reforma, mudança e internacionalização. Anais. Brasília, DF: Unesco Brasil; Sesu, 2003.

YIN, R. K. Estudo de caso: planejamento de métodos. 4. ed. Porto Alegre: Bookman, 2010. 